\title{
WHETHER ENERGY PRODUCTION CAN GET OUT OF THE ENVIRONMENTAL TRAP? A CASE STUDY FOR REGIONAL ENERGY SECTORS IN ZHEJIANG PROVINCE, CHINA
}

\author{
WANG, K. ${ }^{1,2^{*}}-$ ZHANG, H. Q. ${ }^{1,2}-$ ZHANG, C. J. ${ }^{3}$ \\ ${ }^{I}$ Business School, Hohai University, 211100 Nanjing, China \\ ${ }^{2}$ Institute for Planning and Decision Research, Hohai University, 211100 Nanjing, China \\ ${ }^{3}$ Postdoctoral Workstation of Business Administration, Hohai University \\ 211100 Nanjing, China \\ ${ }^{*}$ Corresponding author \\ e-mail:wangkai_hhubs@hhu.edu.cn \\ (Received 25 $5^{\text {th }}$ Sep 2018; accepted $27^{\text {th }}$ Nov 2018)
}

\begin{abstract}
Energy production in Zhejiang Province is facing huge pressure from environmental emissions, while energy production has recently been in surplus. The aim of this paper was to measure the energy efficiency of Zhejiang, from the perspective of industrial and environmental influence factors and the undesirable environmental outputs were considered respectively. We used the principal component analysis model to achieve accurate dimension reduction of input parameters and applied the slack-based model to analyze the environmental energy efficiency of each decision-making units, eleven prefecturelevel cities of Zhejiang from 2005 to 2015. Conceptually, this paper classified the status of environmental energy efficiency into four types: High Level, Decreasing Trend, Improving Trend, and Deteriorating Trend. Empirically, the environmental energy efficiency of Zhejiang was more influenced by pure technical efficiency, and scale efficiency had less effect on technical efficiency. Consequently, Hangzhou reached the effective level and Zhoushan was close to that level, while the situation of energy production overcapacity and environmental pollution reduction of the remaining nine decision-making units have not been substantially improved in recent years.
\end{abstract}

Keywords: principal component, data envelopment analysis, environmental energy efficiency, undesirable environmental outputs, case study, sustainable policy

Abbreviations:

The following abbreviations are used in this manuscript:

Principal Component Analysis

\begin{tabular}{ll|l} 
PCA & PE \\
DEA & Data Envelopment Analysis & PTE
\end{tabular}

SBM Slack-based Model $\quad$ CRS

DMU Decision-making Unit $\quad$ VRS

\begin{tabular}{ll|l} 
TE Technical Efficiency & RTS
\end{tabular}

Scale Efficiency

Pure Technical Efficiency

Constant Returns to Scale

Variable Returns to Scale

Returns to Scale

\section{Introduction}

With the rapid development of the economy and the low efficiency of energy use, the tarp of environmental quality degradation caused by excessive consumption of energy has increasingly become a bottleneck restricting the sustainable development of Chinese economy (Li et al., 2017; Geng and Doberstein, 2008). In the process of rapid economic development, the improvement of energy use efficiency can greatly alleviate the energy resources depletion and improve the environmental welfare level of energy use (Färe et al., 2007). Thus, improving energy efficiency is increasingly concerned by Chinese governments and energy producers. Zhejiang Province is one of the regions with the highest level of economic development in China. It has a high degree of 
industrialization and a large amount of energy consumption. With rapid advancement of industrialization and the rapid economic growth, the total amount of pollution emissions from energy production is still at a high level. In 2015, the Zhejiang total industrial wastewater discharge amounted to 1.47 billion tons, with a total of 2.68 trillion cubic meters of industrial air emissions, and 46.78 million tons of industrial solid waste (Statistics, 2015).

The aim of this research was to understand the extent of efficiency and the optimization potential of the regional energy sectors in the Zhejiang Province of China by using the principal component analysis (PCA) and data envelopment analysis (DEA). In this research, we focused on the evaluation concerning whether the energy decisions were economically efficient, such as the energy facilities investment, the cost of energy generating and transmitting and energy consumption. Especially, we measured the energy efficiency and its impact factors at an industrial and environmental level for Zhejiang Province in view of undesirable environmental outputs including the industrial waste water, solid industrial waste, and industrial waste gas. Meanwhile, two methodologies were suggested in this study as basic paths for assessing the energy efficiency, namely principal component analysis combined with DEA (PCA-DEA), which were used to improve discrimination power.

The energy consumption structure of China, which is dominated by mineral fuels, has led to an increasingly serious problem of environmental pollution (Cao et al., 2012; Shi et al., 2011). Thus, a series of previous studies have focused on the environmental performance of China. Typically, China is currently facing many serious challenges, such as strong energy demands, energy shortages and substantial energy consumption (Chen and Gong, 2017; Gillingham et al., 2009), which are related to the traditional evaluations about the economic concepts, such as energy cost and revenue. However, undesirable output factors generated from energy consumption, especially in the mineral fuels oriented energy industries, should be added to the researching framework of energy efficiency, likewise the process of the official evaluation of environmental performance (Cao et al., 2012; Zhao et al., 2016b). In 1997, the International Energy Agency (IEA) published the first Energy Efficiency Report, and updated it every year (Agency, 2013, 2014). The parameters obtained in that report can be used to estimate the energy efficiency across various economic activities, and the parameters were selected from micro-enterprises, industry levels, and macro-policies. Policymakers can increase energy consumption based on economic output growth or reduce energy consumption according to reduced economic output for improving energy efficiency.

Zhejiang is located on the southeast coast of China, and it is south of the Yangtze River Delta. It has 11 prefecture-level cities under its jurisdiction, and GDP in 2015 reached 4.3 trillion yuan, up $8.0 \%$ over the previous year, accounting for $6.2 \%$ of the national total (Provincial Bureau of Statistical of Zhejiang, 2015). Thus, it is one of the most economically viable provinces in China. In 2015, the Zhejiang total discharge of industrial wastewater, industrial air emission and industrial solid waste, represent a decrease of $1.36 \%, 0.43 \%$, and $0.46 \%$ as compared to 2014 (Statistics, 2014, 2015). Although the environmental burden brought by industrial production has slightly reduced, the total amount of undesirable environmental outputs in terms of absolute numbers is still large. Meanwhile, in 2015, the recently added power supply capacity in Zhejiang was about 7.00 million kilowatts. The total electricity consumption in Zhejiang was 355.39 billion $\mathrm{kWh}$, up $1.4 \%$ over the same period of last year. The maximum power consumption of the electricity load was 58.50 million kilowatts, an 
increase of only 760,000 kilowatts, and only $11 \%$ of the newly added power supply (Provincial Bureau of Statistical of Zhejiang, 2015), which highlighted the overcapacity situation of power generation. Energy production in Zhejiang is not only facing huge pressure from environmental emissions, but also in surplus. Thus, the energy efficiency of Zhejiang has become a subject worth studying. Incorporating undesirable environmental outputs into energy efficiency studies can help us find out which undesirable environmental outputs affect energy efficiency in the province and provide research data for Zhejiang to enhance its energy efficiency by saving energy and reducing emissions. The map of Zhejiang Province is shown in Figure 1.

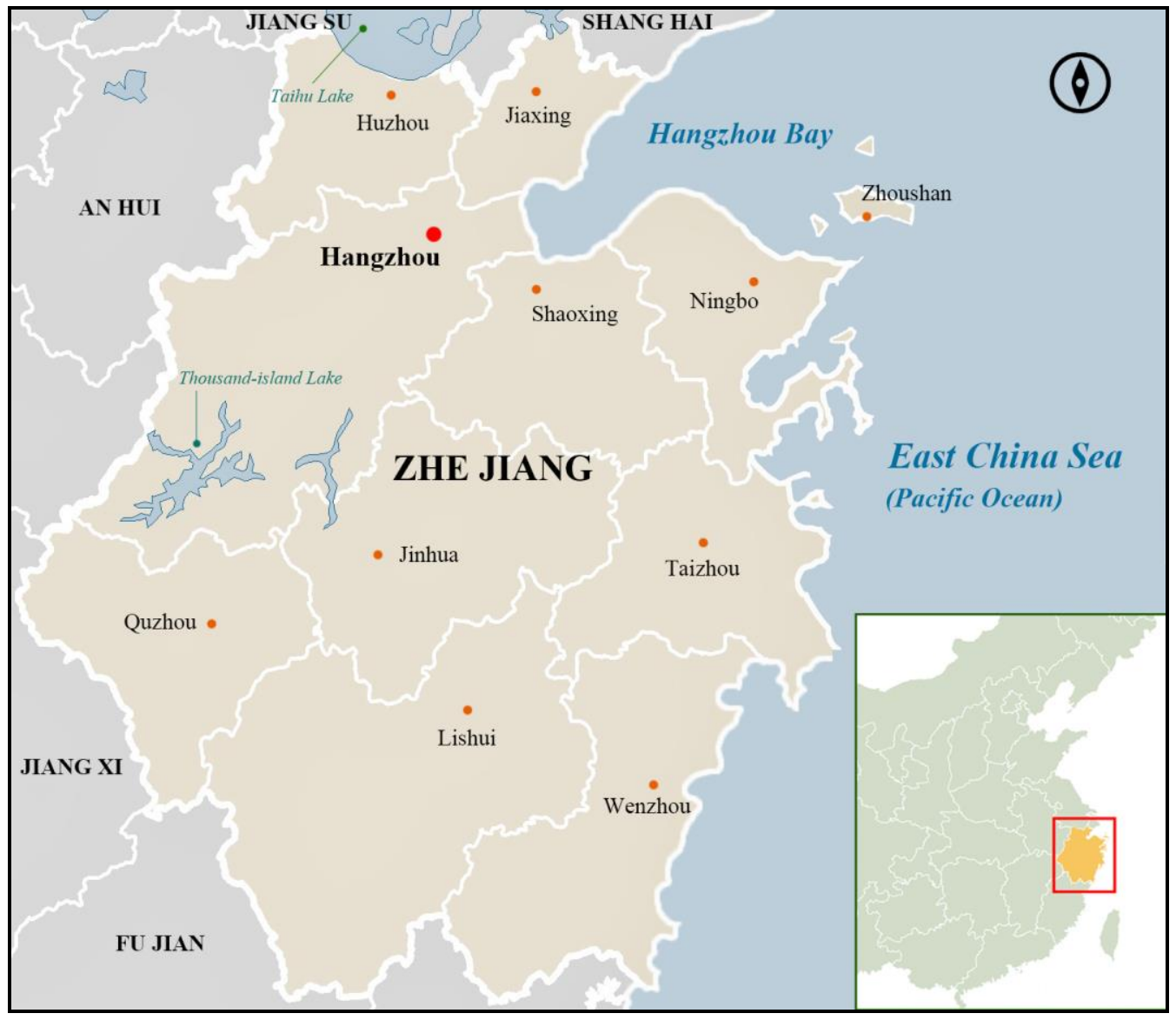

Figure 1. Zhejiang Province of China, by eleven prefecture-level cities

Performance measurement is used to evaluate the performance of decision-making units (DMUs), and it is also a multicriteria decision-making (MCDM) problem (Chang and Lee, 2012). Because stochastic frontier analysis (SFA) (Kumbhakar and Lovell, 2000) and data envelopment analysis (Banker et al., 1984; Charnes et al., 1978) as two kinds of MCDM tools were put forward first, they have been applied to performance measurement for efficiency analysis as effective tools. However, Wang (2003) analyzed that the error existing in the DEA mathematic models can lead to the output efficiency frontier being distorted, while the date used in the DEA is subject to statistical deviation. In addition, due to the DEA techniques ratio between the inputs and outputs of each DMU via a weighting method, the efficiency estimates of a DMU are biased when a slack variable analysis of DEA is calculated. 
To deal with the shortages of DEA, Adler and Golany $(2001,2002)$ proposed a methodology that produces uncorrelated linear combinations of original inputs and outputs to improve discrimination in DEA with minimal loss of information by using principal components. This kind of measuring tool assumes that the separation of variables standing for similar themes such as fixed-asset investment and energy resource input, and the removal of principal components with little or no explanatory power improves the categorization of efficient and inefficient DMUs. Fu and Ou (2013) combined principal PCA and DEA to enhance the efficiency of DMUs more accurately in evaluating the energy performance of Taiwanese Bureau cases. Ghosh and Jintanapakanont (2004) used PCA to understand the latent structure of critical risk factors in Thailand. Due to the fact that the explanatory power of DEA is relatively weak when analyzing several DMUs, Adler and Yazhemsky (2010) further concluded that PCA-DEA outperformed PCA variable reduction by comparing their discrimination performance in a simulation exercise. Thus, the literature review showed that the integration of DEA with PCA technology could obtain more stable estimation results when compared to single MCDM oriented methods. Therefore, this research attempted to combine DEA with PCA to construct a performance analysis model for energy efficiency of the Zhejiang Province, China.

In the process of the industrialization of China, when evaluating the production activities of regional energy sectors, researchers mainly considered the capital, labor, economic output and other parameters, focusing on the enterprise, industry, or regional economic level (Cao et al., 2012; Chen and Gong, 2017; Wang et al., 2016; Zha et al., 2016; Zhang et al., 2016; Zhao et al., 2016a). Studies such as that conducted by Yang and Zhao (2009) revealed that the department of manufacturing was the main hampering factor of the total-fact energy efficiency of Zhejiang Province from 19902007. Wu (2008) and Qiang et al. (2005) calculated the coal consumption rate of heating and energy investment efficiency of the Northern Zhejiang Province and proposed potential energy saving assignments. These research works performed to date only considered economic output and ignored hazardous impacts on the environment in the process of energy efficiency evaluations, therefore the research results were incompatible with reality. Thus, how to coordinate the future energy development with environmental protection and consider the doubt requirement of economy and cleanliness are great subjects. In addition, with the promotion of energy efficiency policies and intensified environmental conditions, the energy and environmental efficiency of the evaluation requirements are becoming higher. Therefore, when analyzing energy efficiency, the industry or region should be considered as non-energy inputs and undesired output factors including a series of emissions of pollutants. Thus, it is necessary and urgent to fill the gaps for the energy efficiency analysis of Zhejiang Province by considering the undesirable output factors of energy consumption through the integration of DEA with PCA methods.

Based on the above consideration, we aimed to measure the energy efficiency and its impact factors at an industrial and environmental level of Zhejiang Province, while considering undesirable environmental outputs including industrial waste water, solid industrial waste, and industrial waste gas by using the integration method that combined PCA with DEA. 


\section{Methodology}

We considered that there are $\mathrm{n}$ independent regions denoted by $D M U_{j}(\mathrm{j}=1,2, \ldots, \mathrm{n})$. In the process of production, each DMU uses $\mathrm{m}$ non-energy inputs $x_{i j}(\mathrm{i}=1,2, \ldots, \mathrm{m})$ and k energy inputs $x_{p j}(\mathrm{p}=1,2, \ldots, \mathrm{k})$ to produce s desirable outputs $y_{r j}(\mathrm{r}=1,2, \ldots, \mathrm{s})$ and $\mathrm{t}$ undesirable outputs $v_{q j}(\mathrm{q}=1,2, \ldots, \mathrm{t})$.

\section{Environmental Production Technology}

The basic thought of environmental production technology is that the general production process can produce some undesirable outputs such as waste water, solid industrial waste, and industrial waste gas. Thus, to minimize the undesirable outputs, it is necessary to arrange certain resources such as environmental protection equipment and manpower, which may lead to the production of desirable outputs in the process of the energy production (Faere et al., 1989; Färe et al., 2007). In this research, we supposed that the energy production process uses capital (C), lobar (L), and energy resources (E) as input factors to produce desirable outputs (Y) and undesirable outputs (V). Thus, the environmental production technology function can be described as follows:

$$
\mathrm{T}=\{(\mathrm{C}, \mathrm{L}, \mathrm{E}, \mathrm{Y}, \mathrm{V}), \text { s.t. }(\mathrm{C}, \mathrm{L}, \mathrm{E}) \text { can produce }(\mathrm{Y}, \mathrm{V})\}
$$

Based on the variable assumptions above, we further specified the environmental production technology for n DMUs as Equation 2, and the detailed environmental production technology function can be modeled as below:

$$
\mathrm{T}=\left(\begin{array}{c}
(\mathrm{C}, \mathrm{L}, \mathrm{E}, \mathrm{Y}, \mathrm{V}) \text { s.t. } \sum_{1}^{\mathrm{j}} \lambda_{\mathrm{j}} \mathrm{C}_{j}, \mathrm{C}, \sum_{1}^{\mathrm{j}} \lambda_{\mathrm{j}} \mathrm{L}_{\mathrm{j}}, \mathrm{L}, \sum_{1}^{\mathrm{j}} \lambda_{\mathrm{j}} \mathrm{E}_{j}, \mathrm{E}, \\
\sum_{1}^{\mathrm{j}} \lambda_{\mathrm{j}} \mathrm{Y}_{\mathrm{j}} . \mathrm{C}, \sum_{1}^{\mathrm{j}} \lambda_{\mathrm{j}} \mathrm{V}_{\mathrm{j}}, \mathrm{V}, \lambda_{\mathrm{j}} . .0, \mathrm{j}=1,2, \ldots, \mathrm{n}
\end{array}\right)
$$

where $\lambda_{\mathrm{j}}$ is the weight variable that is utilized to construct a convex combination enveloping all DMUs; and $\mathrm{j}$ denotes the total number of DMUs.

\section{Principal Component Analysis Model for Variable Reduction}

Principal component analysis (PCA) is a widely used tool for multivariate analysis to achieve accurate dimension reduction by extracting a few, but not all, of the principal components (PCs). PCA can be used to describe most of the variations in the original multivariate data with the least loss of information (Adler and Yazhemsky, 2010). Through the mathematic tool of linear transformation, PCA can decompose correlated variables into uncorrelated PCs under the system of the given dataset. After obtaining the extracted PCs, these calculated PCs are estimated as the projections on the eigenvectors of the covariance or correlation matrix of this dataset ( $\mathrm{Fu}$ and $\mathrm{Ou}, 2013)$. Normally, after the formation of the new composite parameters, the PCs of the parameters parameters need to reflect the original parameters of more than $80 \%$ information, and the new parameters are independent. If the requirements for independence are not met, then the new parameters need to be analyzed for principal component analysis until they meet all the conditions (Jolliffe and Ian, 2005).

Suppose that there are $\mathrm{n}$ independent regions, denoted by $X_{i}(\mathrm{I}=1,2, \ldots, \mathrm{n})$, and each region has $\mathrm{m}$ standardized variables on different factors, which are connected with the 
input-factors and output factors, marked as $X_{j}(\mathrm{j}=1,2, \ldots, \mathrm{m})$. Thus, the standardized variables matrix can be presented in Equation 3.

$$
X=\left[\begin{array}{cccc}
x_{11} & x_{12} & \cdots & x_{1 m} \\
x_{21} & x_{22} & \cdots & x_{2 m} \\
\vdots & \vdots & \vdots & \vdots \\
x_{n 1} & x_{n 2} & \ldots & x_{n m}
\end{array}\right]=\left(X_{1}, X_{2}, \ldots, X_{m}\right)
$$

Based on the standardized variables matrix shown above, the PCA is the process of transferring the original standardized variables into a new systematic variables dataset. To present the relationships between the original standardized variable and PCs, we supposed there were $\mathrm{t} P C s$, denoted as $f_{c}(\mathrm{c}=1,2, \ldots, \mathrm{t}, \mathrm{t} \leq \mathrm{m})$. The equations set can be described as follows:

$$
\left\{\begin{array}{c}
f_{1}=\theta_{11} x_{1}+\theta_{12} x_{2}+\cdots+\theta_{1 m} x_{m} \\
f_{2}=\theta_{21} x_{1}+\theta_{22} x_{2}+\cdots+\theta_{2 m} x_{m} \\
\vdots \quad \vdots \quad \vdots \quad \vdots \quad \vdots \quad \vdots \\
f_{t}=\theta_{t 1} x_{1}+\theta_{t 2} x_{2}+\cdots+\theta_{t m} x_{m}
\end{array}\right.
$$

By using the matrix, Equation 4 can be presented as follows:

$$
\begin{gathered}
F=A X \\
\text { s.t. } F=\left[\begin{array}{c}
f_{1} \\
f_{2} \\
\cdots \\
f_{t}
\end{array}\right], \quad A=\left[\begin{array}{cccc}
\theta_{11} & \theta_{12} & \cdots & \theta_{1 m} \\
\theta_{21} & \theta_{22} & \cdots & \theta_{2 m} \\
\vdots & \vdots & \vdots & \vdots \\
\theta_{t 1} & \theta_{t 2} & \cdots & \theta_{t m}
\end{array}\right], X=\left[\begin{array}{c}
X_{1} \\
X_{2} \\
\cdots \\
X_{m}
\end{array}\right]
\end{gathered}
$$

Normally, Equations 4 and 5 should meet the following conditions:

(i) There is no correlation between $f_{i}$ and $f_{j}(\mathrm{i} \neq \mathrm{j}$ and $\mathrm{i}, \mathrm{j}=1,2, \ldots, \mathrm{t}), \mathrm{ie}, \operatorname{cov}\left(f_{i}, f_{j}\right)=0$.

(ii) $f_{1}$ is the largest variance of $\mathrm{x}_{1}, \mathrm{x}_{2}, \ldots, \mathrm{x}_{\mathrm{m}}$ in all linear combinations. $f_{2}$ is the largest variance of $x_{1}, x_{2}, \ldots, x_{m}$ in all linear combinations, and there is no correlation between $f_{1}$ and $f_{2} . f_{c}(\mathrm{c} \leq \mathrm{t})$ is the largest variance of $x_{1}, x_{2}, \ldots, x_{m}$ in all linear combinations, and there is no correlation between $f_{1}, f_{2}, \ldots, f_{c}$.

(iii) The coefficient matrix $A$ is an orthogonal matrix.

After satisfying the above conditions, $f_{1}, f_{2}, \ldots, f_{c}$ are the principal components of the variables $x_{1}, x_{2}, \ldots, x_{m}$. If the first few PCs of the variance and the proportion of the total variance is greater or equal to $85 \%$, we can use the new variable $f_{1}, f_{2}, \ldots, f_{c}$, instead of the original variable $x_{1}, x_{2}, \ldots, x_{m}$. Thus, the PCA can retain most of the original variable information.

\section{Slack-based Model for Economic-Environmental Energy Efficiency}

In the radial DEA model, the measurement of inefficiency degree only includes the proportion of all input-output reductions. For the inefficient DMU, the difference 
between its current state and a strong effective target not only includes the proportionally improved portion, but also the slack movement. However, the slack movement is not reflected in the measurement of efficiency in the radial model. With this consideration, Tone $(2001,2002)$ proposed the Slack-based Model (SBM) and solved the inefficiency calculated by the measurement of radial model did not include the slack movement. The equation of SBM can be shown as follow:

$$
\begin{aligned}
\min \rho= & \frac{1-\frac{1}{\mathrm{~m}} \sum_{i=1}^{\mathrm{m}} s_{i}^{-} / x_{i k}}{1+\frac{1}{\mathrm{q}} \sum_{r=1}^{\mathrm{q}} s_{r}^{+} / y_{r k}} \\
\text { s.t. } \quad & X \lambda+s^{-}=x_{k} \\
& X \lambda-s^{+}=x_{k} \\
& \lambda, s^{-}, s^{+} \ldots 0
\end{aligned}
$$

where the SBM model uses $\rho$ as the efficiency value of the DMU, and measures the inefficiency from both inputs and outputs, which is the reason why it is called the nonoriented model. $x_{i k} \neq 0(I=1,2, \ldots, m), y_{r k} \neq 0(r=1,2, \ldots, q)$. The inefficiency of inputs and outputs can be presented as Equation 8. If the efficiency value $\rho$ of the SBM model is 1 , this indicates that the evaluated DMU has a strong efficiency. The projection of DUM can be shown by Equation 9.

$$
\begin{gathered}
1-\frac{1}{\mathrm{~m}} \sum_{i=1}^{\mathrm{m}} s_{i}^{-} / x_{i k}, 1+\frac{1}{\mathrm{q}} \sum_{r=1}^{\mathrm{q}} s_{r}^{+} / y_{r k} \\
\hat{x}_{k}=x_{k}-s^{-}, \hat{\mathrm{y}}_{k}=y_{k}+s^{+}
\end{gathered}
$$

\section{Empirical Analysis}

In this section, we first selected three kinds of parameters as inputs as well as desirable and undesirable output factors to evaluate the energy efficiency of Zhejiang Province. Second, we used the PCA model to achieve accurate dimension reduction of input factors, which included two kinds of parameters: non-energy inputs and energy inputs factors. Third, we applied the SBM-DEA model to analyze the energy efficiency of each DMU for eleven prefecture-level cities of Zhejiang Province from 2005 to 2015. In addition, to evaluate the energy efficiency abatement potential of each city in Zhejiang Province, the average energy efficiency parameters of each city from 2014 to 2015 were applied so as to analyze the space-time distribution by using a GIS visualization method and the PCA-BEA model. Finally, we estimated the energy efficiency optimization potential through the projection analysis connected with each DMU.

\section{Variable Selection}

This research selected non-energy inputs and energy inputs as input factors and categorized the output factors into desirable outputs and undesirable outputs. Based on 
the methods of measuring traditional energy efficiency used by $\mathrm{Fu}$ and $\mathrm{Ou}$ (2013) and Ghosh and Jintanapakanont (2004), we selected five parameters as input factors, nonenergy inputs, and energy puts. The non-energy inputs included labor and investment of fixed assets. The energy inputs were coal, oil, and natural gas, which are industry consumption oriented and the unit was converted to the standard coal equivalent. Particularly, in order to estimate the environmental energy efficiency of each DMU, we added three undesirable output factors such as waste gas, solid waste, and waste water into the variable list. Furthermore, we chose GDP as a desirable output factor. The variables of inputs and outputs are shown in Table 1.

Table 1. The variables of inputs and outputs

\begin{tabular}{|c|c|c|c|c|}
\hline Para & leter & Units & Abbr. $^{b}$ & Data Sources \\
\hline Non-energy inputs & $\begin{array}{c}\text { Labor } \\
\text { Investment of fixed } \\
\text { assets }\end{array}$ & $\begin{array}{c}\text { 10-thousand } \\
\text { persons } \\
100 \text { million RMB } \\
\text { yuan }\end{array}$ & $\begin{array}{l}\text { Labor } \\
\text { IFA }\end{array}$ & $\begin{array}{c}\text { Zhejiang Statistics } \\
\text { Year Book } \\
(2006-2016)\end{array}$ \\
\hline Energy inputs & $\begin{array}{l}\text { Coal (Industry } \\
\text { Consumption) } \\
\text { Oil (Industry } \\
\text { Consumption) } \\
\text { Natural gas } \\
\text { (Industry } \\
\text { Consumption) } \\
\end{array}$ & $\begin{array}{l}\text { 10-thousand tons of } \\
\text { SCE } \\
\text { 10-thousand tons of } \\
\text { SCE } \\
\text { 10-thousand tons of } \\
\text { SCE }\end{array}$ & Coal & $\begin{array}{c}\text { China Energy } \\
\text { Statistical Yearbook } \\
(2006-2016)\end{array}$ \\
\hline Desirable output & $\begin{array}{l}\text { Gross Domestic } \\
\text { Product }\end{array}$ & $\begin{array}{c}\text { 100-million RMB } \\
\text { yuan }\end{array}$ & GDP & $\begin{array}{c}\text { Zhejiang Statistics } \\
\text { Year Book } \\
(2006-2016)\end{array}$ \\
\hline Undesirable outputs & $\begin{array}{c}\text { Waste gas } \\
\text { Solid wastes } \\
\text { Waste water }\end{array}$ & $\begin{array}{l}\text { 10-thousand tons } \\
10 \text {-thousand tons } \\
10 \text {-thousand tons }\end{array}$ & $\begin{array}{l}\text { WG } \\
\text { SW } \\
\text { WW }\end{array}$ & $\begin{array}{c}\text { Zhejiang } \\
\text { Environment } \\
\text { Statistical Yearbook } \\
(2006-2016) \\
\end{array}$ \\
\hline
\end{tabular}

${ }^{a}$ SCE denotes standard coal equivalent

${ }^{\mathrm{b}}$ Abbr. will be used in this research paper

\section{Data Collection and Treatment}

In the Zhejiang Province of China, there are eleven prefecture-level cities, the capital Hangzhou (HgZ), Ningbo (NB), Jiaxing (JX), Huzhou (HuZ), Shaoxing (SX), Zhoushan (ZS), Wenzhou (WZ), Jinhua (JH), Quzhou (QZ), Taizhou (TZ), and Lishui (LS). The data estimated in this research were collected from the Zhejiang Statistics Year Book and Zhejiang Environment Statistical Yearbook. In general, Chinese national statistical agencies publish economic, social and environmental statistics for the previous year. Thus, the data required for this research period (2005-2015) comes from the statistical yearbooks published by the official statistical agencies from 2006 to 2016 . The sources of the data is presented in Table 1. In order to avoid the data interference caused by the time value of price, we converted the GDP and investment of fixed assets under the interest basement of 2015. The descriptive statistics of the dataset are shown in Table 2.

Both the variables of inputs and outputs shown in Table 2 fall into two categories: non-energy inputs and energy inputs, desirable output and undesirable outputs. First, the non-energy inputs and desirable output, Labor, Fixed-Asset Investment (IFA), and GDP of each city were obtained directly from the Zhejiang Statistics Year Book. Second, all kinds of energy consumption factors were converted into standard coal equivalents based on the conversion factors from physical units to coal equivalents obtained from 
the China Energy Statistical Yearbook. Third, to estimate the environmental effect of the undesirable outputs, we chose waste gas, solid waste, and waste water, which are pollutants produced by the energy production activities and obtained from the Zhejiang Environment Statistical Yearbook, as output factors. In particularly, based on the logical relationships between the inputs and outputs, we took the data of the undesirable outputs and transformed them into another series of parameters, $\mathrm{WG}^{*}, \mathrm{SW}^{*}, \mathrm{WW}^{*}$, which are the inverse of each other and can be described as follows:

$$
\mathrm{WG}^{*}=\mathrm{WG}^{-1}, \mathrm{SW}^{*}=\mathrm{SW}^{-1}, \mathrm{WW}^{*}=\mathrm{WW}^{-1}
$$

Table 2. The descriptive statistics of the dataset

\begin{tabular}{|c|c|c|c|c|c|c|c|c|c|c|}
\hline \multicolumn{2}{|c|}{ Year $^{\mathrm{a}}$} & \multicolumn{5}{|c|}{ Inputs } & \multicolumn{4}{|c|}{ Outputs } \\
\hline & & \multicolumn{2}{|c|}{ Non-energy inputs } & \multicolumn{3}{|c|}{ Energy inputs ${ }^{b}$} & \multirow{2}{*}{$\begin{array}{c}\text { Dd.output }^{\mathbf{c}} \\
\text { GDP }\end{array}$} & \multicolumn{3}{|c|}{ Undesirable outputs } \\
\hline & & Labor & IFA & Coal & Oil & NG & & WG & SW & WW \\
\hline \multirow{4}{*}{2006} & Max & 55.84 & 130.61 & 222.76 & 3.82 & 0.22 & 335.20 & 196.58 & 66.04 & $4,257.38$ \\
\hline & Min & 512.21 & $1,502.77$ & $2,287.05$ & 39.27 & 2.24 & $3,441.51$ & $2,018.29$ & 678.02 & $43,710.67$ \\
\hline & Mean & 290.39 & 673.50 & 949.38 & 16.30 & 0.93 & $1,428.61$ & 837.82 & 281.45 & $18,144.82$ \\
\hline & Std. dev. & 155.99 & 454.08 & 674.25 & 11.58 & 0.66 & $1,014.60$ & 595.02 & 199.89 & $12,886.43$ \\
\hline \multirow{4}{*}{2009} & Max & 65.95 & 279.19 & 283.66 & 6.89 & 0.35 & 533.26 & 279.48 & 91.73 & $4,772.79$ \\
\hline & Min & 597.47 & $2,291.65$ & $2,712.17$ & 65.87 & 3.34 & $5,098.66$ & $2,672.22$ & 877.06 & $45,634.05$ \\
\hline & Mean & 315.72 & 965.94 & $1,099.19$ & 26.70 & 1.35 & $2,066.39$ & $1,083.00$ & 355.46 & $18,494.64$ \\
\hline & Std. dev. & 169.64 & 652.66 & 787.50 & 19.13 & 0.97 & $1,480.45$ & 775.91 & 254.66 & $13,250.30$ \\
\hline \multirow{4}{*}{2012} & Max & 72.90 & 471.98 & 317.85 & 4.98 & 0.97 & 853.18 & 395.57 & 111.99 & $4,324.99$ \\
\hline & Min & 644.43 & $3,722.75$ & $2,906.62$ & 45.56 & 8.85 & $7,802.01$ & $3,617.38$ & $1,024.07$ & $39,550.43$ \\
\hline & Mean & 332.13 & $1,548.84$ & $1,171.96$ & 18.37 & 3.57 & $3,145.81$ & $1,458.55$ & 412.91 & $15,946.91$ \\
\hline & Std. dev. & 188.99 & $1,030.52$ & 846.07 & 13.26 & 2.58 & $2,271.04$ & $1,052.96$ & 298.09 & $11,512.50$ \\
\hline \multirow{4}{*}{2015} & Max & 74.50 & 751.52 & 315.98 & 7.20 & 1.41 & $1,092.85$ & 539.15 & 133.14 & $2,202.16$ \\
\hline & Min & 663.03 & $5,556.32$ & $2,905.87$ & 66.24 & 13.00 & $10,050.21$ & $6,268.99$ & $1,155.41$ & $33,807.05$ \\
\hline & Mean & 336.97 & $2,419.92$ & $1,131.27$ & 25.79 & 5.06 & $3,912.58$ & $2,440.23$ & 407.81 & $13,395.75$ \\
\hline & Std. dev. & 192.46 & $1,538.06$ & 830.96 & 18.94 & 3.72 & $2,873.93$ & $1,752.86$ & 299.09 & $10,000.96$ \\
\hline
\end{tabular}

a The research duration is from 2005 to 2015 . Due to the limited space, this statistic table only shows the descriptive statistics of the research duration typically. For more details, please contact the author to obtain the data for Zhejiang Province from 2015 to 2015; ${ }^{\mathrm{b}}$ The units of the energy input factors is conversed into standard coal equivalent according to the Table 1; ${ }^{\mathrm{c}}$ D.d outputs are the abbreviation of Desirable outputs

As the input and output data have different dimensions, the amount of the data varied greatly, thus the original data can be transformed to eliminate the dimensional influence, and this method allows the input and output data to be in a positive range. The data transformed processing method can be shown as follows: 


$$
\left\{\begin{array}{l}
x_{i j}^{\prime}=0.1+\frac{x_{i j}-\min _{j}\left\{x_{i j}\right\}}{\max _{j}\left\{x_{i j}\right\}-\min \left\{x_{i j}\right\}} \\
x_{p j}^{\prime}=0.1+\frac{x_{p j}-\min _{j}\left\{x_{p j}\right\}}{\max _{j}\left\{x_{p j}\right\}-\min \left\{x_{p j}\right\}} \\
y_{r j}^{\prime}=0.1+\frac{y_{r j}-\min _{j}\left\{y_{r j}\right\}}{\max _{j}\left\{y_{r j}\right\}-\min \left\{y_{r j}\right\}} \\
v_{q j}^{\prime}=0.1+\frac{v_{q j}-\min _{j}\left\{v_{q j}\right\}}{\max _{j}\left\{v_{q j}\right\}-\min \left\{v_{q j}\right\}}
\end{array}\right.
$$

where the $\mathrm{m}$ non-energy inputs $\mathrm{x}_{\mathrm{ij}}(\mathrm{I}=1,2, \ldots, \mathrm{m})$ and $\mathrm{k}$ energy inputs $\mathrm{x}_{\mathrm{pj}}(\mathrm{p}=1,2, \ldots, \mathrm{k})$ produce $\mathrm{s}$ desirable outputs $\mathrm{y}_{\mathrm{rj}}(\mathrm{r}=1,2, \ldots, \mathrm{s})$, and $\mathrm{t}$ undesirable outputs $\mathrm{v}_{\mathrm{qj}}(\mathrm{q}=1,2, \ldots, \mathrm{t})$. The transformed inputs are $\mathrm{x}_{\mathrm{ij}}^{*} \in[0.1,1], \mathrm{x}_{\mathrm{pj}}^{*} \in[0.1,1]$, and the transformed outputs are $\mathrm{y}_{\mathrm{rj}}{ }_{\mathrm{j}} \in[0.1,1], \mathrm{v}_{\mathrm{qj}}{ }_{\mathrm{j}} \in[0.1,1]$.

\section{Comprehensive Analysis of Environmental Energy Efficiency}

In this section, nine parameters of energy and environment of Zhejiang Province were selected. First, the PCA was used to eliminate the overlapping information among the input parameters and generate the corresponding principal components. Second, based on the PCA-DEA model, we calculated the environmental energy efficiency of 11 DMUs. Third, according to the analysis results, this section focuses on the evaluation of the comprehensive technical efficiency (TE), pure technical efficiency (PTE), and scale efficiency (SE) of the environmental energy in the cities of Zhejiang Province. In addition, based on the energy efficiency data, we obtained the potential of improvement concerning environmental energy efficiency of each city. Finally, based on the efficiency adjustment, this paper provides an explanation of the different development trends of environmental energy efficiency in each DMU, and puts forward suggestions for improvement.

\section{Evaluation of Environmental Energy Efficiency}

We used the PCA-DEA model to quantitatively estimate the environmental energy performance of Zhejiang Province from 2005 to 2015. This study found that in the 11 years since 2005, the average level of environmental energy efficiency in the 11 cities in Zhejiang Province showed a pyramid shape. First, the comprehensive performance of environmental energy in Hangzhou, Zhoushan, and Lishui was higher than 0.800, accounting for $27 \%$ of the total number of cities. Second, the comprehensive performance levels of Jinhua, Taizhou, Jiaxing, Wenzhou, and Shaoxing were relatively low, in fact below the level of 0.500 , accounting for $45 \%$ of the total number of cities. Finally, Quzhou, Huzhou, and Ningbo were at an intermediate stage of overall efficiency at above 0.50 , but below 0.80 , accounting for $27 \%$ of the total number of cities, same as the number of first-class cities with excellent overall efficiency in Zhejiang Province. The technical efficiency (TE) of each DMU from 2005 to 2015 is shown in Table 3.

From the perspective of the overall efficiency of the city distribution, there was a difference in the amount between cities at the front of efficiency and cities that did not reach the most efficient. As the capital of Zhejiang Province, the input-output status of Hangzhou constitutes to be the frontier of environmental energy performance. Although 
Zhoushan and Lishui have not achieved optimal status, the average TE in 11 years was higher than 0.80 and the potential for environment and energy performance improvement was relatively less. Compared to the first three cities, the TE of Quzhou, Huzhou, and Ningbo were relatively poor, and energy production activities on the environment had a greater direct and indirect impact. In particularly, it should be noted that the average comprehensive performance of five cities in Zhejiang Province was below 0.50 .

Table 3. The technical efficiency score of each DMUs (2005-2015)

\begin{tabular}{c|ccccccccccc|c}
\hline DMUs $^{\mathbf{a}}$ & $\mathbf{2 0 0 5}$ & $\mathbf{2 0 0 6}$ & $\mathbf{2 0 0 7}$ & $\mathbf{2 0 0 8}$ & $\mathbf{2 0 0 9}$ & $\mathbf{2 0 1 0}$ & $\mathbf{2 0 1 1}$ & $\mathbf{2 0 1 2}$ & $\mathbf{2 0 1 3}$ & $\mathbf{2 0 1 4}$ & $\mathbf{2 0 1 5}$ & Mean \\
\hline Hangzhou & 1.00 & 1.00 & 1.00 & 1.00 & 1.00 & 1.00 & 1.00 & 1.00 & 1.00 & 1.00 & 1.00 & $1.00^{* * *}$ \\
Zhoushan & 1.00 & 0.61 & 1.00 & 1.00 & 1.00 & 1.00 & 1.00 & 1.00 & 1.00 & 1.00 & 1.00 & $0.96^{* * *}$ \\
Lishui & 0.91 & 1.00 & 0.86 & 0.87 & 0.90 & 0.91 & 0.90 & 0.90 & 0.88 & 0.90 & 0.54 & $0.87^{* * *}$ \\
Quzhou & 0.80 & 0.60 & 0.77 & 0.79 & 0.78 & 0.80 & 0.78 & 0.81 & 0.81 & 0.84 & 0.27 & 0.73 \\
Huzhou & 0.57 & 0.44 & 0.57 & 0.57 & 0.59 & 0.62 & 0.63 & 0.63 & 0.63 & 0.63 & 0.42 & 0.57 \\
Ningbo & 0.50 & 0.42 & 0.51 & 0.50 & 0.51 & 0.59 & 0.73 & 0.56 & 0.58 & 0.54 & 0.39 & 0.53 \\
Jinhua & 0.43 & 0.33 & 0.44 & 0.45 & 0.46 & 0.48 & 0.48 & 0.48 & 0.48 & 0.48 & 0.57 & $0.46^{*}$ \\
Taizhou & 0.40 & 0.37 & 0.40 & 0.40 & 0.43 & 0.44 & 0.45 & 0.47 & 0.47 & 0.47 & 0.62 & $0.45^{*}$ \\
Jiaxing & 0.41 & 0.32 & 0.42 & 0.42 & 0.44 & 0.46 & 0.46 & 0.46 & 0.47 & 0.47 & 0.27 & $0.42^{*}$ \\
Wenzhou & 0.41 & 0.31 & 0.40 & 0.41 & 0.43 & 0.45 & 0.42 & 0.43 & 0.43 & 0.43 & 0.42 & $0.41^{*}$ \\
Shaoxing & 0.39 & 0.30 & 0.39 & 0.39 & 0.40 & 0.42 & 0.42 & 0.43 & 0.43 & 0.43 & 0.31 & $0.39^{*}$ \\
\hline
\end{tabular}

${ }^{\text {a }}$ The city ranking is in descending order of Mean

*The average score of technical efficiency below the 0.500

*** The average score of technical efficiency better than 0.800

Despite historical reasons such as the crude made energy production mode, the lack of environmental protection concept and the relative backwardness of energy production technology, the average TE of the overall 11 years was relatively low. However, we should pay more attention to the fact that in 2015, the TE of four cities, including Quzhou, Huzhou, Ningbo, Jiaxing, , remained below 0.50. Thus, Zhejiang Province still faces great challenges in improving energy efficiency, and at least eight cities (excluding Hangzhou, Zhoushan, and Lishui) have certain potential for improvement. The overall environmental and energy performance of 11 cities in Zhejiang Province from 2005 to 2015 are shown in Figure 2.

Based on the efficiency score changing tendency from 2005 to 2015 within 11 citied from Figure 2, we choose the score of 0.50 as the average level. The performance score from less than 0.50 to greater than 0.50 is considered to be a performance improvement, whereas performance is considered a deterioration. Thus, we can clearly know about the environmental energy performance trend of 11 cities in Zhejiang Province, including the technical efficiency (TE), pure technical efficiency (PTE), and scale efficiency (SE), which are presented in Table 4.

The trend of environmental performance in 11 cities can be divided into four categories. The first category is High Level, which means the overall efficiency is maintained at 1.00 for the whole research period. Such cities include Hangzhou and Zhoushan. The second category is Decreasing Trend, which means that the overall historical efficiency showed a state of greater than 0.50 , but the declining tendency was 
less than 0.50 in recent years. Such cities include Lishui, Quzhou, Huzhou, and Ningbo. The third type of city is the Improving Trend, where the overall efficiency of such cities is gradually improving. In recent years, the improvement has been remarkable and above 0.50. Such cities include Jinhua and Taizhou. In the fourth category, Deteriorating Trend, the overall technical efficiency of such cities has been at a longterm low level and shows a deteriorating trend. Such cities include Jiaxing, Wenzhou, and Shaoxing. The tendency of these four types, on the one hand, made us realize that the environmental energy performance among cities in Zhejiang Province is at different levels, and on the other hand, there are some commonalities between the regions, which can provide a research path for finding common influencing factors between the regions.
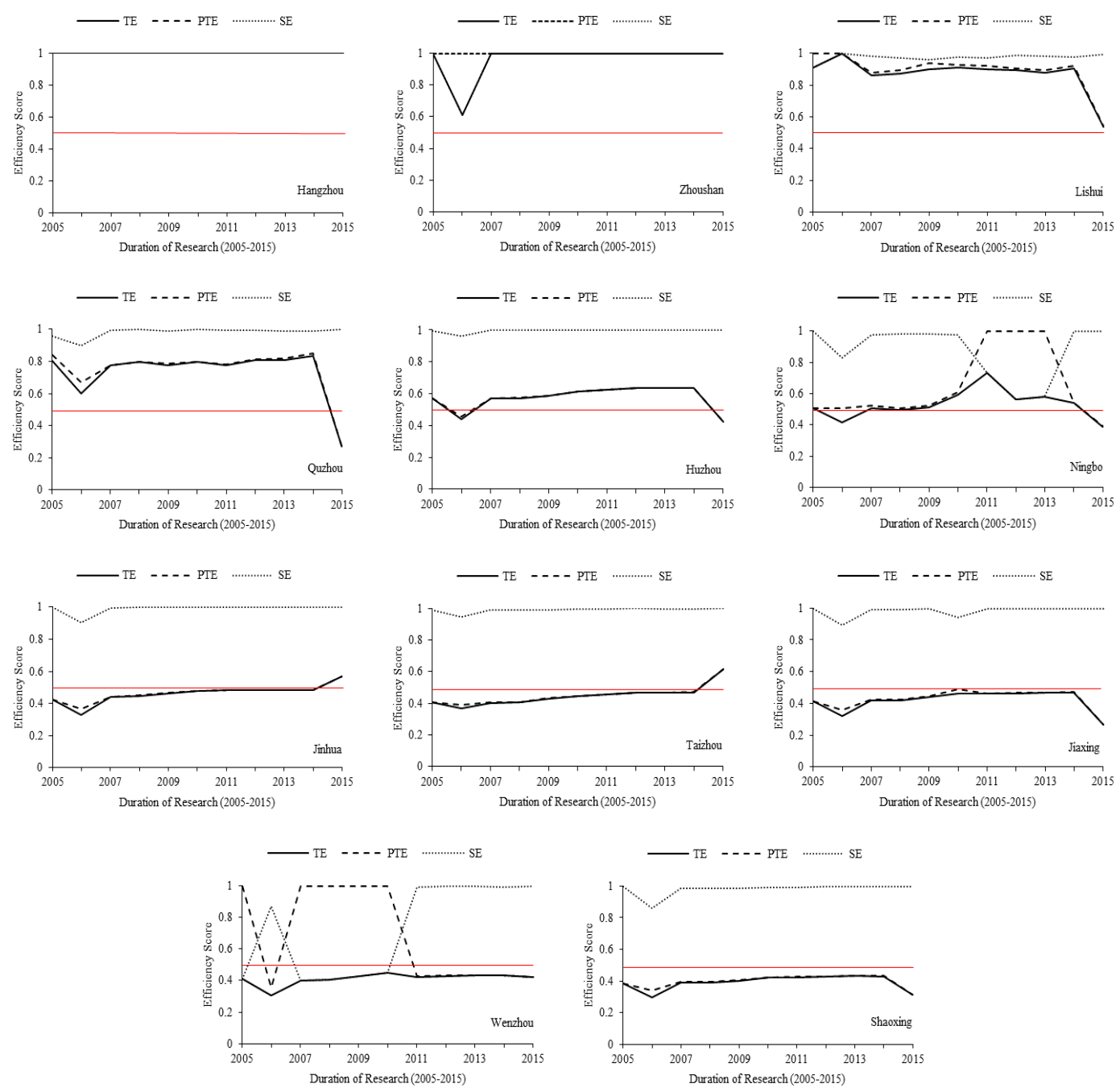

Figure 2. Efficiency score of eleven prefecture-level cities of Zhejiang Province (2005-2015)

${ }^{a}$ The red line (-) of each graph shows the level of efficiency score is 0.50

${ }^{b}$ The graph of Hangzhou shows both the TE, PTE and SE are 1.00. The graph of Zhoushan, the TE and PTE of 2006 are 0.61, thus the line of TE and PTE are combined with each, which is the same situation for Huzhou, Jinhua, Taizhou, and Shaoxing

${ }^{c}$ Technical efficiency (TE), Pure technical efficiency (PTE), Scale efficiency (SE) 
Table 4. Four types of environmental energy efficiency tendency (Zhejiang Province Experience)

\begin{tabular}{|c|c|c|c|c|}
\hline No. & Tendency Description & DMUs Included & Count & Tendency Graph \\
\hline 1 & $\begin{array}{c}\text { High Level. The TE of DMUs maintains the } \\
\text { level of 1.00. If there have been a relatively } \\
\text { small number of lower levels in history, the } \\
\text { type of the DUM also can be classified as } \\
\text { High Level. }\end{array}$ & $\begin{array}{l}\text { Hangzhou; } \\
\text { Zhoushan }\end{array}$ & 2 & \\
\hline 2 & $\begin{array}{l}\text { Decreasing Trend. There has been a middle } \\
\text { level (better than 0.05) of TE in history, but } \\
\text { the TE of DMUs started to decreasing and be } \\
\text { lower than } 0.50 \text { recently can be classified as } \\
\text { this type. }\end{array}$ & $\begin{array}{l}\text { Lishui; Quzhou; } \\
\text { Huzhou; Ningbo }\end{array}$ & 4 & \\
\hline 3 & $\begin{array}{l}\text { Improving Trend. Although the TE of } \\
\text { DMUs were lower than } 0.50 \text {, the TE started } \\
\text { to improve and better than } 0.50 \text { recently can } \\
\text { be classified as this type. }\end{array}$ & Jinhua; Taizhou & 2 & \\
\hline 4 & $\begin{array}{l}\text { Deteriorating Trend. The TE of DMUs } \\
\text { maintains the low level, which is always } \\
\text { lower than } 0.50 \text { and can not be shown the } \\
\text { improving tendency in the recent research } \\
\text { duration (2013-2015) can be classified as this } \\
\text { type. }\end{array}$ & $\begin{array}{l}\text { Jiaxing; Wenzhou; } \\
\text { Shaoxing }\end{array}$ & 3 & \\
\hline
\end{tabular}

a The red line (-) of each graph shows the level of efficiency score is 0.50

\section{Space Distribution of Environmental Energy Efficiency}

For the slack-based model, the returns to scale of energy production technology is variable (Variable return to scale, VRS). Thus, the efficiency value obtained from the VRS model is just the technical efficiency. The scale efficiency value can be separated by comparing and calculating the efficiency values of both the CRS and VRS, and the calculation method can be shown as follows:

$$
\mathrm{SE}=\mathrm{TE} / \mathrm{PTE}
$$

We averaged the environmental energy efficiency data of Zhejiang Province in 2014 and 2015, and presented the geographical distribution of comprehensive energy efficiency, pure technical efficiency, and scale efficiency in Zhejiang Province by using GPS technology. Hangzhou and Zhoushan are at the forefront of environmental energy efficiency, followed by Lishui City. However, the technical efficiency scores of Jiaxing, Shaoxing, Ningbo, Wenzhou are under 0.5, and worse than cities marked green. Based on the logical relationship between integrated energy efficiency, purely technical efficiency, and economies of scale (Equation 9), we found that due to the small number differences of SE between the eleven cities, and the insensitive impact on TE, the comprehensive efficiency was more affected by the PTE, which makes the TE and PTE closer to the data distribution structure. In addition, the economies of scale of Hangzhou and Zhoushan are in a constant state, while the economies of scale of other cities are in a decreasing state. This shows that the marginal efficiency of environmental energy brought by the increase of the scale of energy equipment decreases, and the improvement of energy and environmental efficiency should be 
studied from the perspective of upgrading PTE. The spatial distribution of the environmental energy efficiency of the 2014 and 2015 average level for Zhejiang Province is shown in Figure 3.

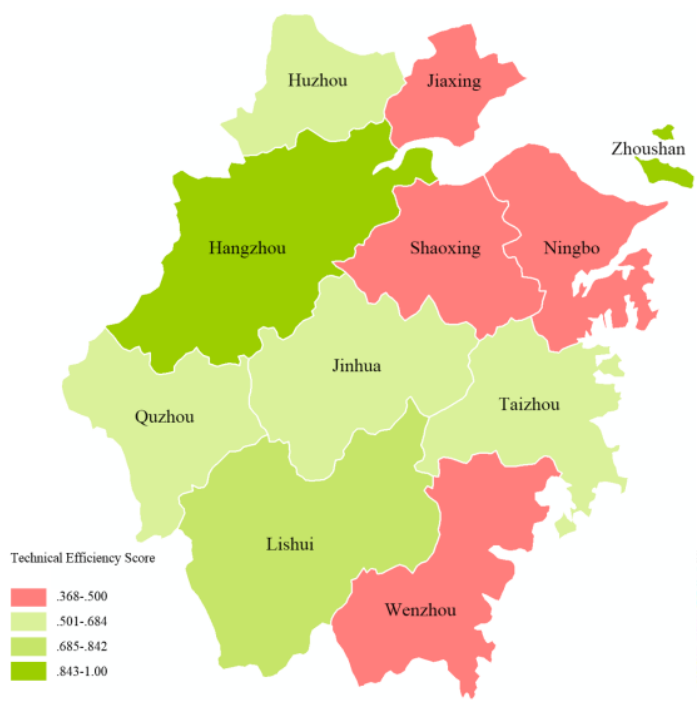

Figure 3.1. TE of each DMU (2014-2015 Average)

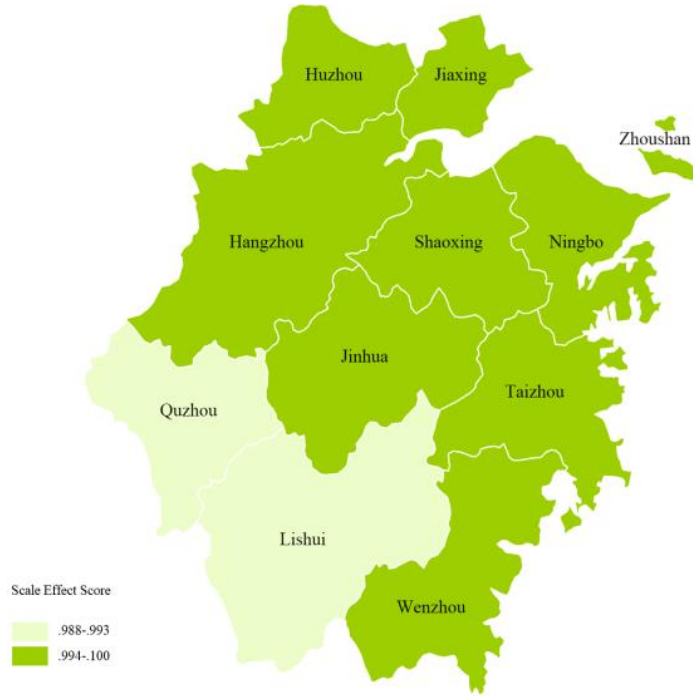

Figure 3.3. SE of each DMU (2014-2015 Average)

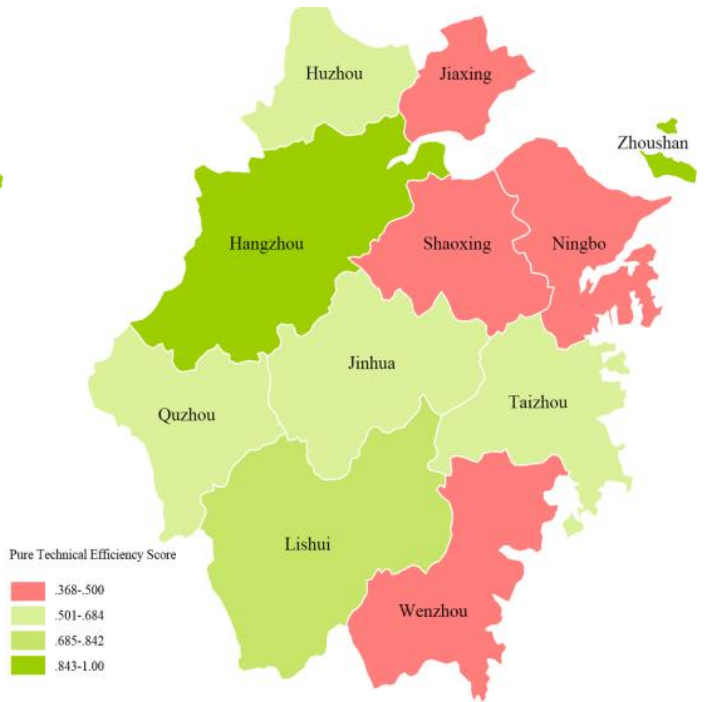

Figure 3.2. PTE of each DMU (2014-2015 Average)

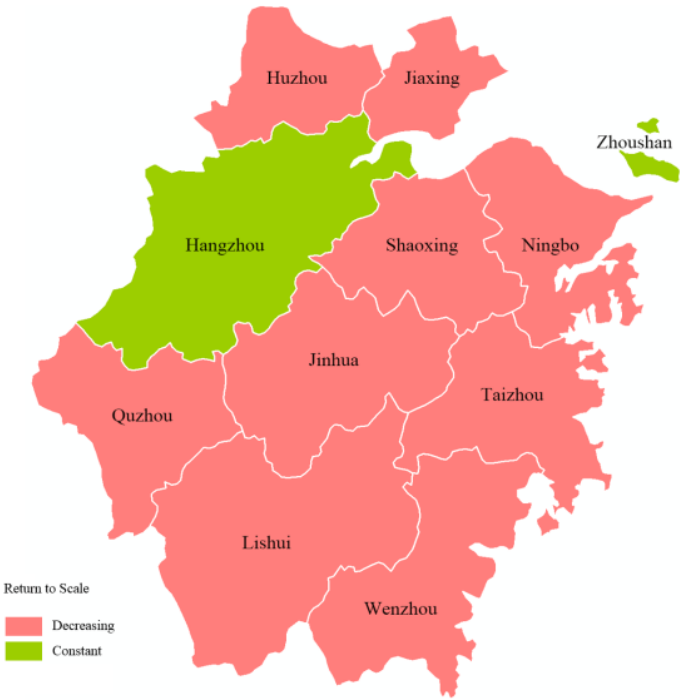

Figure 3.4. RTS of each DMU (2014-2015 Average)

Figure 3. The Space distribution of environmental energy efficiency for Zhejiang (2014-2015 Average). ${ }^{a}$ Technical efficiency (TE), Pure technical efficiency (PTE), Scale efficiency (SE)

\section{Estimation of Environmental Energy Efficiency Optimization Potential}

DMUs with strong environmental energy performance make up the efficiency frontier and have become an improved reference for non-effective DMUs. Hangzhou and Zhoushan had a strong and effective environment energy performance with input and output factors in a balanced and effective state, which provides a performance reference for other cities to improve their environmental efficiency. The SBM-DEA is a non-radial improvement DEA model and we provided the slack movement and projection per city. Since this paper used a non-dimensional data processing approach, 
all production technology elements had values between 0.10 and 1.00 (see Equation 8 for details). Although non-dimension eliminates the inconsistency between variables, it does not affect the research on environmental energy efficiency improvement, and the proportion between slack movement and projection (see Table 5).

Table 5. The slack movement and projection of each DMU in 2015 (Zhejiang Province)

\begin{tabular}{|c|c|c|c|c|c|c|c|c|c|c|}
\hline \multirow{3}{*}{ DMUs } & \multirow{3}{*}{$\begin{array}{l}\text { CRS } \\
\text { Score }\end{array}$} & \multicolumn{5}{|c|}{ Slack Movement of Inputs } & \multicolumn{4}{|c|}{ Slack Movement of Outputs } \\
\hline & & \multicolumn{2}{|c|}{ Non-energy inputs } & \multicolumn{3}{|c|}{ Energy inputs } & \multirow{2}{*}{$\begin{array}{c}\text { Dd.output }^{\mathrm{a}} \\
\text { GDP }\end{array}$} & \multicolumn{3}{|c|}{ Undesirable outputs } \\
\hline & & Labor & IFA & Coal & Oil & NG & & WG & SW & WW \\
\hline Hangzhou & $1.00^{* * * *}$ & $\begin{array}{c}0.00 \\
(1.000)^{\mathrm{b}}\end{array}$ & $\begin{array}{c}0.00 \\
(1.00)\end{array}$ & $\begin{array}{c}0.00 \\
(1.00)\end{array}$ & $\begin{array}{c}0.00 \\
(1.00)\end{array}$ & $\begin{array}{c}0.00 \\
(1.00)\end{array}$ & $\begin{array}{c}0.00 \\
(1.00)\end{array}$ & $\begin{array}{c}0.00 \\
(0.74)\end{array}$ & $\begin{array}{c}0.00 \\
(0.60)\end{array}$ & $\begin{array}{c}0.00 \\
(1.00)\end{array}$ \\
\hline Zoushan & $0.96^{* * *}$ & $\begin{array}{c}0.00 \\
(0.10)\end{array}$ & $\begin{array}{c}0.00 \\
(0.18)\end{array}$ & $\begin{array}{c}0.10 \\
(0.10)\end{array}$ & $\begin{array}{c}0.00 \\
(0.10)\end{array}$ & $\begin{array}{c}0.00 \\
(0.10)\end{array}$ & $\begin{array}{c}0.00 \\
(0.10)\end{array}$ & $\begin{array}{c}0.01 \\
(0.10)\end{array}$ & $\begin{array}{c}0.00 \\
(0.10)\end{array}$ & $\begin{array}{c}0.00 \\
(0.10)\end{array}$ \\
\hline Lishui & 0.87 & $\begin{array}{c}0.00 \\
(0.21)\end{array}$ & $\begin{array}{c}0.00 \\
(0.10)\end{array}$ & $\begin{array}{c}0.01 \\
(0.10)\end{array}$ & $\begin{array}{c}0.01 \\
(0.10)\end{array}$ & $\begin{array}{c}0.00 \\
(0.10)\end{array}$ & $\begin{array}{c}0.00 \\
(0.10)\end{array}$ & $\begin{array}{c}0.01 \\
(0.14)\end{array}$ & $\begin{array}{c}0.01 \\
(0.14)\end{array}$ & $\begin{array}{c}0.02 \\
(0.21)\end{array}$ \\
\hline Quzhou & 0.73 & $\begin{array}{c}0.00 \\
(0.20)\end{array}$ & $\begin{array}{l}0.00 \\
(0.13)\end{array}$ & $\begin{array}{c}0.01 \\
(0.11)\end{array}$ & $\begin{array}{c}0.01 \\
(0.11)\end{array}$ & $\begin{array}{c}0.00 \\
(0.01)\end{array}$ & $\begin{array}{c}0.00 \\
(0.11)\end{array}$ & $\begin{array}{c}0.11 \\
(0.39)\end{array}$ & $\begin{array}{c}0.10 \\
(0.48)\end{array}$ & $\begin{array}{c}0.18 \\
(0.43)\end{array}$ \\
\hline Huzhou & 0.57 & $\begin{array}{c}0.01 \\
(0.28)\end{array}$ & $\begin{array}{c}0.01 \\
(0.23)\end{array}$ & $\begin{array}{c}0.01 \\
(0.21)\end{array}$ & $\begin{array}{c}0.02 \\
(0.21)\end{array}$ & $\begin{array}{c}0.00 \\
(0.21)\end{array}$ & $\begin{array}{c}0.00 \\
(0.21)\end{array}$ & $\begin{array}{c}0.12 \\
(0.49)\end{array}$ & $\begin{array}{c}0.39 \\
(0.56)\end{array}$ & $\begin{array}{c}0.16 \\
(0.45)\end{array}$ \\
\hline Ningbo & 0.53 & $\begin{array}{c}0.00 \\
(0.84)\end{array}$ & $\begin{array}{c}0.00 \\
(0.88)\end{array}$ & $\begin{array}{c}0.30 \\
(0.87)\end{array}$ & $\begin{array}{c}0.21 \\
(0.87)\end{array}$ & $\begin{array}{c}0.01 \\
(0.87)\end{array}$ & $\begin{array}{c}0.00 \\
(0.87)\end{array}$ & $\begin{array}{c}0.11 \\
(1.00)\end{array}$ & $\begin{array}{c}0.13 \\
(1.00)\end{array}$ & $\begin{array}{c}0.10 \\
(0.54)\end{array}$ \\
\hline Jjinhua & 0.46 & $\begin{array}{c}0.00 \\
(0.561)\end{array}$ & $\begin{array}{c}0.00 \\
(0.33)\end{array}$ & $\begin{array}{c}0.01 \\
(0.36)\end{array}$ & $\begin{array}{c}0.17 \\
(0.36)\end{array}$ & $\begin{array}{c}0.00 \\
(0.36)\end{array}$ & $\begin{array}{c}0.00 \\
(0.36)\end{array}$ & $\begin{array}{c}0.01 \\
(0.24)\end{array}$ & $\begin{array}{c}0.03 \\
(0.20)\end{array}$ & $\begin{array}{c}0.01 \\
(0.27)\end{array}$ \\
\hline Taizhou & 0.45 & $\begin{array}{c}0.14 \\
(0.53)\end{array}$ & $\begin{array}{c}0.00 \\
(0.36)\end{array}$ & $\begin{array}{c}0.12 \\
(0.37)\end{array}$ & $\begin{array}{c}0.03 \\
(0.37)\end{array}$ & $\begin{array}{c}0.00 \\
(0.38)\end{array}$ & $\begin{array}{c}0.00 \\
(0.37)\end{array}$ & $\begin{array}{c}0.15 \\
(0.38)\end{array}$ & $\begin{array}{c}0.15 \\
(0.38)\end{array}$ & $\begin{array}{c}0.12 \\
(0.34)\end{array}$ \\
\hline Jiaxing & 0.42 & $\begin{array}{c}0.00 \\
(0.53)\end{array}$ & $\begin{array}{l}0.00 \\
(0.47)\end{array}$ & $\begin{array}{c}0.01 \\
(0.37)\end{array}$ & $\begin{array}{c}0.08 \\
(0.37)\end{array}$ & $\begin{array}{c}0.01 \\
(0.37)\end{array}$ & $\begin{array}{c}0.00 \\
(0.37)\end{array}$ & $\begin{array}{c}0.03 \\
(0.40)\end{array}$ & $\begin{array}{c}0.02 \\
(0.49)\end{array}$ & $\begin{array}{c}0.01 \\
(0.72)\end{array}$ \\
\hline Wenzhou & 0.41 & $\begin{array}{c}0.11 \\
(0.52)\end{array}$ & $\begin{array}{c}0.14 \\
(0.51)\end{array}$ & $\begin{array}{c}0.21 \\
(0.49)\end{array}$ & $\begin{array}{c}0.19 \\
(0.49)\end{array}$ & $\begin{array}{c}0.00 \\
(0.49)\end{array}$ & $\begin{array}{c}0.00 \\
(0.49)\end{array}$ & $\begin{array}{c}0.01 \\
(0.75)\end{array}$ & $\begin{array}{c}0.53 \\
(0.79)\end{array}$ & $\begin{array}{c}0.28 \\
(0.49)\end{array}$ \\
\hline Shaoxing & 0.39 & $\begin{array}{c}0.00 \\
(0.56)\end{array}$ & $\begin{array}{c}0.00 \\
(0.48)\end{array}$ & $\begin{array}{c}0.03 \\
(0.48)\end{array}$ & $\begin{array}{c}0.11 \\
(0.48)\end{array}$ & $\begin{array}{c}0.01 \\
(0.48)\end{array}$ & $\begin{array}{c}0.00 \\
(0.48)\end{array}$ & $\begin{array}{c}0.02 \\
(0.29)\end{array}$ & $\begin{array}{c}0.12 \\
(0.33)\end{array}$ & $\begin{array}{c}0.34 \\
(0.86)\end{array}$ \\
\hline
\end{tabular}

${ }^{\text {a }}$ D.d outputs are the abbreviation of Desirable outputs

b Inside the "( )" is the Projection Value for each variable factors. All the values have been dimensioned

${ }^{c}$ Strong efficient of DMUs will be noted as $* * *$, and the slack movement of each variables will be 0.00

\section{(1) Efficiency Improvement from the Perspective of Environmental Energy Efficiency Distribution Structure in DMUs}

According to the research ideas provided by environmental production theory, we selected nine variables between input and output, and highlighted the negative output variables brought by energy production to the environment. For Hangzhou and Zhoushan, energy production not only contributed to GDP in an effective manner, but also had a negative impact on the environment in an effective state. There was a certain degree of improvement necessary for Zhoushan for the input factor for energy production, and the negative output of waste gas.

\section{(2) Efficiency Improvement from the Perspective of Input Factor}

There was a big difference between the non-energy inputs and energy input factors in the improvement level. According to the infomation mentioned above, the economies of scale of cities are generally high. Since the contribution of energy infrastructure to environmental energy performance improvement contribution is limited, the labor and energy infrastructure investment in fixed assets is not sensitive to improving 
environmental efficiency. However, the input structure of energy resources is more sensitive to the improvement of environmental energy performance. Coal and oil are helpful for reducing environmental pollution and improving environmental energy efficiency.

\section{(3) Efficiency Improvement from the Perspective of the Output Factor}

There is a positive interaction between energy input and national economic development. Compared with the energy production waste gas, the improved demand of solid waste and waste water is greater, which should arouse the attention of environmental managers.

\section{Discussion}

SBM-DEA is a non-radial improvement DEA model (Gang, 2014) and we provided the slack movement and projection per city. For the energy input structure, Hangzhou and Zhoushan as the frontier environmental energy efficiency had their input and output factors in a balanced and effective state, which provided a performance reference for other cities to improve in terms of environmental efficiency. Cities, where environmental energy performance did not reach an effective level, have more room for improvement in coal and oil than in natural gas. This shows that reducing coal and oil inputs and increasing the share of clean energy in the energy mix are instructive for improving environmental and energy performance in Zhejiang Province. This result agreed with the study of Zhengge and Leike (2011) which found that increasing the proportion of clean energy in energy consumption has a significant impact on improving energy environmental performance.

Technical efficiency can be divided into pure technical efficiency and scale efficiency (Gang, 2014). However, environmental energy performance of Zhejiang Province is more influenced by pure technical efficiency, and scale efficiency has less effect on technical efficiency because the scale efficiency of $80 \%$ of cities is effective and the difference in scale efficiency is small in space. Especially, the low efficiency of pure technology suggests that energy consumption and production methods need to be adjusted, such as improving power generation technology and reducing the proportion of coal used (Watanabe and Tanaka, 2007). There is a clear difference in pure technical efficiency between eastern and western of Zhejiang Province. Cities with low efficiency of pure technology are mostly distributed on the eastern coast of Zhejiang, while the situation in western and central Zhejiang is relatively modest. Especially, Hangzhou as the capital of Zhejiang has remained in an effective state of pure technical efficiency over the years. Hong and Baofu (2015) suggest the spatial differences in energy performance are influenced by industrial agglomeration distribution and government regulation. Due to the imbalance of economic and technological development in space, energy production enterprises will make different decisions on the choice of energy resources and production methods based on cost considerations (Yeh et al., 2010).

General evolution of economies of scale in production shows that the production efficiency will go through three stages in succession, namely, increasing scale benefits, constant scale benefits, and decreasing scale benefits (Gans et al., 2011). Hangzhou and Zhoushan are in the stage of constant scale benefits, while other cities are in the stage of decreasing scale benefits. $\mathrm{Xu}$ (2015) suggest that in 2015, the energy production industry of Shandong Province, one of the Chinese eastern coastal provinces, mostly use 
coal as a thermoelectric energy source. $55 \%$ of these power plants are small thermal power, which is defined as the generating capacity is below $5.0 \times 10^{4} \mathrm{~kW}$ and these power plants form decreasing scale benefits in the energy production. However, Zhoushan has abundant wind energy resources, accounting for $1 / 3$ of the province's wind energy resources. The wind power, as a kind of clean energy source, installed capacity of Zhoushan is $9.78 \times 10^{4} \mathrm{~kW}$ in 2013 , accounting for $26.6 \%$ of the total installed capacity within Zhejiang Province (Haichun et al., 2013). Thus, our research evidenced the view again by showing significant decreasing scale benefits in the energy production industry of Chinese eastern coastal cities.

\section{Conclusion}

This paper studied the environmental energy efficiency of Zhejiang Province from 2005 to 2015. We added the undesirable outputs of energy production as one of the most important factors to study the output efficiency. To improve discrimination in DEA with minimal loss of information, we used dimensionality reduction, a methodology that produces uncorrelated linear combinations of original inputs and outputs. Besides, we obtained the energy performance parameters of 11 cities in Zhejiang Province for 11 years, which include technical efficiency, pure technical efficiency and scale efficiency, projection value and slack movement of each variable by SBM model.

Eleven prefecture-level environmental energy performance trends in the city could be divided into four categories: High Level, Decreasing Trend, Improving Trend, and Deteriorating Trend. These trends were more influenced by pure technical efficiency, while scale efficiency had less effect on technical efficiency. Hangzhou reached the effective level and Zhoushan was close to it, while the remaining urban environmental energy performance did not reach the effective level. From the changing tendencies of environment energy performance, the performance level of Hangzhou and Zhoushan remained in an effective status, while Jinhua and Taizhou showed a gradual improvement trend, and the remaining cities showed signs of deterioration or no improvement in environmental energy efficiency. In particular, the inflection points of this trend change existed more in 2014 and 2015, and the statistics on energy production overcapacity and environmental pollution in Zhejiang Province have not been substantially improved in recent years. Therefore, the government should vigorously strengthen the policy supervision and adjust energy consumption structure in the energy resources investment. At the same time, energy producer should accelerate technological innovation, and coordinate the development of energy and environmental protection to improve the environmental energy efficiency of high energy-consumption industries.

Acknowledgements. This study was supported by the Postgraduate Research and Practice Innovation Program of Jiangsu Province (No. KYCX17_0512), the Foundation of the Humanities and Social Science Research of the Ministry of Education (No. 17YJC790194) and the China Scholarship Council (No. 201806710133).

Author contributions. Kai Wang and Hengquan Zhang designed the research. Kai Wang performed the research, collected, analyzed the data and wrote the manuscript. Kai Wang edited the manuscript and Chenjun Zhang provided the guidance during research. 


$$
-650-
$$

\section{REFERENCES}

[1] Adler, N., Golany, B. (2001): Evaluation of deregulated airline networks using data envelopment analysis combined with principal component analysis with an application to Western Europe. - European Journal of Operational Research 132: 260-273.

[2] Adler, N., Golany, B. (2002): Including principal component weights to improve discrimination in data envelopment analysis. - Journal of the Operational Research Society 53: 985-991.

[3] Adler, N., Yazhemsky, E. (2010): Improving discrimination in data envelopment analysis: PCA-DEA or variable reduction. - European Journal of Operational Research 202: 273-284.

[4] Banker, R. D., Charnes, A., Cooper, W. W. (1984): Some models for estimating technological and scale inefficiencies in Data Envelopment Analysis. - Management Science 30(9): 1031-1142.

[5] Cao, J., Ho, M. S., Jorgenson, D. (2012): An Integrated Assessment of the Economic Costs and Environmental Benefits of Pollution and Carbon Control. - In: Aoki, M., Wu, J. (eds.) The Chinese Economy. International Economic Association Series. Palgrave Macmillan, London.

[6] Chang, P. T., Lee, J. H. (2012): A fuzzy DEA and knapsack formulation integrated model for project selection. - Computers \& Operations Research 39: 112-125.

[7] Charnes, A., Cooper, W. W., Rhodes, E. (1978): Measuring the efficiency of decision making units. - European Journal of Operational Research 2: 429-444.

[8] Chen, X., Gong, Z. (2017): DEA Efficiency of Energy Consumption in China's Manufacturing Sectors with Environmental Regulation Policy Constraints. Sustainability 9: 210.

[9] Faere, R., Grosskopf, S., Lovell, C. A. K., Pasurka, C. (1989): Multilateral Productivity Comparisons When Some Outputs are Undesirable: A Nonparametric Approach. Review of Economics \& Statistics 71: 90-98.

[10] Färe, R., Grosskopf, S., Pasurka Jr, C. A. (2007): Environmental production functions and environmental directional distance functions. - Energy 32(7): 1055-1066.

[11] Färe, R., Grosskopf, S., Pasurka Jr, C. A. (2007): Pollution abatement activities and traditional productivity. - Ecological Economics, 62(3-4): 673-682.

[12] Fu, H. P., Ou, J. R. (2013): Combining PCA With DEA to Improve the Evaluation of Project Performance Data: A Taiwanese Bureau of Energy Case Study. - Project Management Journal 44: 94-106.

[13] Gang, C. (2014): Data Envelopment Analysis: Methods and MaxDEA Software. Intellectual Property Publishing House.

[14] Gans, J., King, S., Stonecash, R., Mankiw, N. G. (2011): Principles of economics. Cengage Learning, Australia.

[15] Geng, Y., Doberstein, B. (2008): Developing the circular economy in China: Challenges and opportunities for achieving 'leapfrog development'. - International Journal of Sustainable Development and World Ecology 15: 231-239.

[16] Ghosh, S., Jintanapakanont, J. (2004): Identifying and assessing the critical risk factors in an underground rail project in Thailand: a factor analysis approach. - International Journal of Project Management 22: 633-643.

[17] Gillingham, K., Newell, R. G., Palmer, K. (2009): Energy Efficiency Economics and Policy. - Annual Review of Resource Economics 1: 597-619.

[18] Haichun, Z., Xiaofen, Y., Zhaodong S., Huisheng, F., Eding, L. (2013): Present situation and development suggestions of new energy development and application in the new district of Zhoushan islands. - Sino-Globay Energy 18(1): 101-106.

[19] Hong, J., Baofu, Z. (2015): Deconstruction, spatial patterns and coupling between energy efficiency and industrial structure in China. - Resources Science 37(1): 152-162. 


$$
-651 \text { - }
$$

[20] International Energy Agency (IEA) (2013): Market Report Series Energy Efficiency 2013. - IEA Publications. Available online: https://www.iea.org/publications/freepublications/publication/EEMR2013_free.pdf.

[21] International Energy Agency (IEA) (2014): Market Report Series Energy Efficiency 2014. - IEA Publications. Available online: https://www.iea.org/Textbase/npsum/EEMR2014SUM.pdf.

[22] Jolliffe, I. (2011): Principal component analysis. - In: International encyclopedia of statistical science. Springer, Berlin, Heidelberg.

[23] Kumbhakar, S. C., Lovell, C. K. (2003): Stochastic frontier analysis. - Cambridge University Press.

[24] Li, H., Dong, L., Xie, Y. T., Fang, M. (2017): Low-carbon benefit of industrial symbiosis from a scope-3 perspective: a case study in China. - Applied Ecology and Environmental Research 15(3): 135-153.

[25] National Bureau of Statistical of China (2006-2016): Energy Statistical Yearbook (20062016). - China Statistics Press.

[26] Provincial Bureau of Statistical of Zhejiang (2006-2016): Zhejiang Statistics Year Book (2006-2016). - China Statistics Press.

[27] Qiang, J. I., Qiang, L. I., Song, H. K., Mosenthal, P. (2005): Research on energy efficiency resources potential and efficiency power plant in Jiangsu. - Power Demand Side Management.

[28] Shi, M., Ma, G., Shi, Y. (2011): How much real cost has China paid for its economic growth. - Sustainability Science 6: 135.

[29] Statistics, Z.P.B.o. (2014): Zhejiang Nature Resources and Statistical Yearbook on Environment. - China Statistics Press.

[30] Statistics, Z.P.B.o. (2015): Zhejiang Nature Resources and Statistical Yearbook on Environment. - China Statistics Press.

[31] Tone, K. (2001): A slacks-based measure of efficiency in data envelopment analysis. European Journal of Operational Research 130: 498-509.

[32] Tone, K. (2002): A slacks-based measure of super-efficiency in data envelopment analysis. - European Journal of Operational Research 143: 32-41.

[33] Wang, S. (2003): Adaptive non-parametric efficiency frontier analysis: a neural-networkbased model. - Computers \& Operations Research 30: 279-295.

[34] Wang, X., Han, L., Yin, L. (2016): Environmental Efficiency and Its Determinants for Manufacturing in China. - Sustainability 9: 47.

[35] Watanabe, M., Tanaka, K. (2007): Efficiency analysis of Chinese industry: a directional distance function approach. - Energy Policy 35(12): 6323-6331.

[36] Wu, C. (2008): Economy Analysis of Architecture Energy Efficiency in Northern Jiangsu Province. - Science \& Technology Information.

[37] Xu, D. (2015): Study of power efficiency based on PCA-DEA. - The Dissertation for master's degree. University of Science and Technology of China.

[38] Yang, Z. Y., Zhao, Y. (2009): An Analysis on Changes and Influencing Factors of Totalfactor Energy Efficiency in Jiangsu. - China Soft Science 18: 1792-1800.

[39] Yeh, T. L., Chen, T. Y., Lai, P. Y. (2010): A comparative study of energy utilization efficiency between Taiwan and China. - Energy Policy 38(5): 2386-2394.

[40] Zha, Y., Zhao, L., Bian, Y. (2016): Measuring regional efficiency of energy and carbon dioxide emissions in China: A chance constrained DEA approach. - Computers \& Operations Research 66: 351-361.

[41] Zhang, M., Song, Y., Li, P., Li, H. (2016): Study on affecting factors of residential energy consumption in urban and rural Jiangsu. - Renewable \& Sustainable Energy Reviews 53: 330-337.

[42] Zhao, L., Zha, Y., Liang, N., Liang, L. (2016a): Data envelopment analysis for unified efficiency evaluation: an assessment of regional industries in China. - Journal of Cleaner Production 113: 695-704. 
[43] Zhao, L., Zha, Y., Wei, K., Liang, L. (2016b): A target-based method for energy saving and carbon emissions reduction in China based on environmental data envelopment analysis. - Annals of Operations Research.

[44] Zhengge, T., Leike, L. (2011): Efficiency evaluation of industrial sectors in China accounting for the energy and environment factors based on provincial data by a SBM approach. - Economic Review 2: 55-65. 